\title{
Quality evaluation in logistic services
}

\author{
Fiorenzo Franceschini \\ Politechnico di Torino, Torino, Italy \\ Carlo Rafele \\ Politechnico di Torino, Torino, Italy
}

\section{Keywords}

Quality, Logistics, Service quality, Measurement, Supply chain

\section{Abstract}

The paper highlights some problems relevant to the quality measurements in logistic services. "Traditional" logistic indicators are compared with the service dimensions defined in the Parasuraman-Zeithaml-Berry model. Furthermore, the problem of service indicators aging is analyzed and discussed. In order to enhance readers' ability to contribute to the development in the field, the authors pose open-ended questions in the article.

International Journal of Agile Management Systems

2/1 [2000] 49-53

(C) MCB University Press [ISSN 1465-4652]

\section{Introduction}

In the industrial sector, the activities connected to the supply of services, in intermediate companies or to the final endusers, are becoming more important compared to the operations directly applied to the products (Teas, 1993; Negri, 1993; Parasuraman et al., 1985).

In such contexts, it has to be noticed that the level of service activities varies drastically for similar working environments. What are the main reasons for these variations? Is it reasonable to introduce a method for service quality evaluation in such a way as to distinguish between bad or good service?

These interesting issues have stimulated the discussion in many meetings and conventions between suppliers and customers of services. The attempts made to come to concrete solutions of the problem are as numerous as the models proposed. The rich literature on the theme is an evident proof of the interest on the matter (Kano et al., 1984; Parasuraman et al., 1985, 1991; Hayes, 1992; Cronin and Taylor, 1994; Franceschini and Rossetto, 1995b, 1998; Franceschini et al., 1998).

Recently, the market development has introduced a supplementary element that increases the interest towards services. In many commercial segments, especially for articles of wide consumption, it is possible to look at a continuous "alignment" of product features and performances (Franceschini and Rossetto 1997, 1998). Often such differences are so small that only very skilled consumers are able to recognize them. The ability to make a product more attractive than another is exclusively played around related services.

In this paper, a special category of services will be considered: the logistic services in

The current issue and full text archive of this journal is available at http://www.emerald-library.com manufacturing. To start with, a typical set of indicators suitable for the evaluation of general performances of a logistic service will be examined. This set will be also compared with a specific set of parameters used by a company leader in this specific sector. An analysis of correspondences with one of the most used models for service quality evaluation is illustrated: the Parasuraman et al. model (PZB model) (Parasuraman et al., 1985, 1988, 1991).

Finally, the problem of "indicators' aging" due to the evolution of quality characteristics in the time is illustrated.

\section{Quality indicators in a logistic system}

Quality evaluation of a logistic service requires a definition of a set of quality indicators.

Table I shows a "classic" set of indicators for a logistic service supplied by an external enterprise to a commitment manufacturing company (Christopher, 1992; Caplice and Sheffi, 1994; Van Amstel and D’hert, 1996; Frizziero and Rafele, 1996).

As can be seen from Table I, the set of indicators covers different aspects of service quality management. For each one, the sphere of competence and the operative definition are repeated. Some indicators define times (for example: lead time), some percentage ratios (regularity, reliability ...), and some other quantities referred to time (productivity).

Cost indicators are not explicitly mentioned. The analysis is conducted in a contractual framework with pre-established resources. In this context, the skill to improve the service quality becomes an element of competitiveness under the same economical burdens for the customer. It must also be remarked that most of the proposed indicators are focalized on the results rather than on the resources used to reach them. Although the set of indicators has a general 
Fiorenzo Franceschini and

Carlo Rafele

Quality evaluation in logistic services

International Journal of Agile

Management Systems

2/1 [2000] 49-53

\section{$\overline{\text { Table I }}$}

List of the main indicators used for the evaluation of a logistic service

\begin{tabular}{|c|c|}
\hline Indicators & Meaning \\
\hline Lead time & $\begin{array}{l}\text { Time occurred from the arrival of a customer order to the receiving of goods; it includes the following } \\
\text { activities: } \\
\text { - order transmission } \\
\text { - order processing: formal order control } \\
\text { customer solvency control } \\
\text { in warehouse availability control } \\
\text { shipping documents preparation } \\
\quad \text { deliveries planning } \\
\text { - order composition: materials drawing by the stock } \\
\quad \text { packaging } \\
\text { composition with other orders } \\
\text { - order transfer to the production plant } \\
\text { - warehouse delivery } \\
\text { - final delivery to the customer }\end{array}$ \\
\hline
\end{tabular}

Regularity Dispersion around the mean value of the delivery lead time number of orders (or $\mathrm{UL}^{(*)}$, or quantity) delivered with a Dt of delay/advance total number of orders (or $U^{(*)}$, or quantity) delivered

Reliability number of orders (or $\mathrm{UL}^{(*)}$, or quantity) delivered to the due date

number of orders (or $\mathrm{UL}^{(*)}$, or quantity) required to the due date

Completeness number of full orders (or $\mathrm{UL}^{(*)}$, or quantity) delivered in a period $* 100$

total number of orders (or $\mathrm{U}^{(*)}$, or quantity) delivered in the same period

Flexibility

number of special/urgent/unexpected orders confirmed to the customer

total number of special/urgent/unexpected orders required by the customer $* 100$

Correctness

number of mistake orders dispatched in a period $* 100=$

total number of orders dispatched in that period

number of mistake invoices/packing lists send to customers in a period

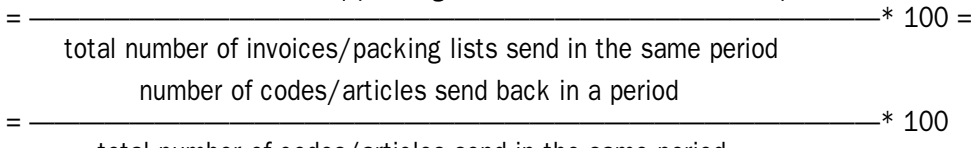

total number of codes/articles send in the same period

Harmfulness

number of "damaged" orders dispatched in a period

total number of orders dispatched in the same period

Productivity

number of items/orders/ codes/quantity delivered

period of time considered

Notes: ${ }^{(*)}$ UL: Units load

Reliability and Completeness indicators might be associated in the following:

Number of full orders (or UL*, or quantity) delivered to the due date

Total number of orders (or UK*, or quantity) required for that date punctual orders)

validity, it can be specialized in relation to some specific needs. An example of specialization can be found in Table II. It shows indicators used by Federal Express to monitor logistic services in manufacturing applications (Colonna, 1997).

It is noted that some indicators are split into more items and that for some others the equivalent indicator does not exist (see for example flexibility). This is due to the specific needs of a deeper control of the moving loads by Federal Express.

However much the differences may be (as indicated in Table II), there are common parameters for the evaluation of quality in a logistic service.

After the definition of the main indicators for the measurement of a logistic service, it is 
Fiorenzo Franceschini and Carlo Rafele

Quality evaluation in logistic services

International Journal of Agile Management Systems 2/1 [2000] 49-53 interesting to compare them with factors which influence service supplying according to the PZB model (Parasuraman et al., 1985,

1990, 1991). These factors are:

- Tangibles (appearance of physical facilities, equipment, personnel, and communication;

- Reliability (ability to perform the promised service dependably and accurately);

- Responsiveness (willingness to help customers and provide prompt service);

- Assurance (knowledge and courtesy of employees and their ability to convey trust and confidence);

- Empathy (caring, individualized attention the firm provides its customers).

Table III shows the comparison between the two sets of parameters.

The analysis has been carried out considering two kinds of relationships. The strong relationship, which identifies a strong link between factors and indicators and a weak relationship. We also suppose that one indicator could interact with more factors because it is not easy to identify a biunique

\section{Table II}

Comparison between the set of proposed indicators and those used by Federal Express

\begin{tabular}{ll}
\hline Proposed indicators & Federal Express indicators \\
\hline Lead time & - \\
Regulatory & Transportation delay \\
& Delay 1 day late \\
Reliability & Delays late for the promised day \\
& Untraceability \\
- & Opening of administrative cases \\
Completeness & Not delivered parcels: uncomplete deliveries \\
Flexibility & - \\
Correctness & Missing parcels: destination mistakes \\
Harmfulness & Invoices correction \\
Productivity & Damaged parcels \\
Source: Colonna, 1997. & Non-despatched calls \\
\hline
\end{tabular}

connection between PZB factors and logistic indicators.

Beyond the detail, it is evident that the empathy factor is not related to any one indicator. It means that aspects connected with customer communications or to service customization are not included in the service evaluation.

A typical case is the exchange of information when there is some disorganization (for example a failure of one or more vehicles). If problems and relative solutions are immediately pointed out to the customer, his reaction will be surely different if he had no information until the last minute.

A possible indicator of the empathy level might be the "timeliness" on the communication of information about the disorganization (expressed in time units). In this way, the customer should be able to get "measures" in short time. So the set of indicators presented above must include other elements that in primis do not seem linked to the service.

A further element to be considered is that the quality expected by a customer varies in time. It can be observed that the "target" values of service attributes evolve with the experience and knowledge of customers and suppliers (Parasuraman et al., 1991; Franceschini and Rossetto, 1995a). As an immediate consequence logistic indicators have to be updated in their meanings and content (Shapiro et al., 1997). A very similar situation happens when a subject is doing a target shooting with a moving target; he has to continually realign the shot.

Now it could be possible to point out some questions. Is it reasonable to define a set of indicators with self-modifying capability to follow the variations of quality attributes? Can we identify some particular steps in service evolution to indicate the aging of quality indicators?

In this matter, we could probably use a classification similar to that proposed by

Table III

Correspondence between logistic indicators and service dimensions identified in the PZB model; "A" strong relationship; "B" weak relationship

\begin{tabular}{|c|c|c|c|c|c|}
\hline & Tangibles & Reliability & Responsiveness & Assurance & Empathy \\
\hline Lead time & B & & A & & \\
\hline Regularity & B & & A & & \\
\hline Relaibility & $B$ & $A$ & & & \\
\hline Completeness & & A & & B & \\
\hline Flexibility & & & A & B & \\
\hline Correctness & & $A$ & & B & \\
\hline Harmfulness & B & & & A & \\
\hline Productivity & A & & & B & \\
\hline
\end{tabular}


Fiorenzo Franceschini and

Carlo Rafele

Quality evaluation in logistic

services

International Journal of Agile

Management Systems

2/1 [2000] 49-53
Kano for quality characteristics of a product/ service (Kano et al., 1984).

It is to be noted that Kano's model provides an attribute classification in three categories:

- Basic (B) (attribute whose presence is accepted without creating satisfaction, but whose absence causes dissatisfaction);

- One-dimensional (O) (attribute whose presence gives satisfaction and absence causes dissatisfaction);

- Excitement (E) (attribute whose presence gives satisfaction, but whose absence is accepted without casing dissatisfaction).

The classification of an attribute to a specific category is not constant in time. More in detail, it may be observed that attributes of a product have a "natural" transition from " $\mathrm{E}$ " towards "O" and also from "O" towards "B". A typical example is the evolution occurring to automotive air-conditioning: at the beginning it was entirely optional, later it became present if requested, and today, especially for the highest market segments, it is no longer optional. A similar evolution exists for quality indicators in a logistic service.

The interpretation of indicators, on the base of Kano's model, suggests a new dimension on how to identify new indicators or on the ways to modify the actual ones.

We may notice that the adoption of a dynamic "set" of indicators should also enjoy the indirect benefit to maintain in a constant "positive" tension the relationship between customer and supplier.

The analysis of external logistic indicators allows the evaluation of supplier service quality. A further step could be the analysis of the links among these and the internal quality indicators. These last elements photograph the internal performances of a company to satisfy customer requirements (for example number of employees, number and type of units load, ways for planning operations, supporting activities and so on). Internal indicators represent the other face of the coin hidden to the customer with regard to the service quality.

An interesting problem is the existence of a link between the two families of indicators. In other words, is it possible to argue or to identify a model that allows evaluating the parameters of the dual family, starting from the information obtained for the other one?

As a first approximation a linear link between the two vectors representing the indicators can be considered:

$$
\mathrm{I}_{\mathrm{e}}=\mathrm{I}_{\mathrm{i}} \cdot \mathrm{A}
$$

where:
$I_{e}$ represents the vector of the external indicators;

$I_{i}$ represents the vector of the internal indicators;

A the matrix that couches the

relationships model between the two families of indicators (it is specific for every company in a well defined period of time).

The definition of some relationships between the two groups of indicators immediately states the matter of the way of estimating the coefficients of the matrix A. A possible way might be that of using a multiple linear regression technique.

Matrix A might be used to carry out previsions or adjustments on the values of indicators of one family, starting from values obtained by the dual family.

\section{Conclusion}

The paper highlights some problems relevant to the quality measurements in logistic services. The traditional logistic indicators are compared with a specific set of parameters used by a company leader in the logistic sector. Subsequently, correspondences existing between a set of indicators for the evaluation of service quality and service factors introduced by the PZB model are analyzed. In the comparison, it appears that, usually, the empathy factor is not included to any indicator, although in some situations its contribution could be very important.

The paper also presents the problem of indicator aging in relation to the evolution of service quality attributes.

In conclusion, a simple model to create a relationship between external logistic indicators and internal supplier performances is provided.

\section{References}

Caplice, C. and Sheffi, Y. (1994), "A review and evaluation of logistics metrics", The International Journal of Logistics Management, Vol. 5 No. 2, pp. 11-28.

Christopher, M. (1992), Logistics and Supply Chain Management, Pitman Publishing, London.

Colonna, F. (1997), "La qualità nella logistica", Logistica Management, No. 77, pp. 49-52.

Cronin, J.J. and Taylor, S.A. (1994), "SERVPERF versus SERVQUAL: reconciling performancebased and perceptions-minus-expectations measurement of service quality", Journal of Marketing, Vol. 58.

Franceschini, F. and Rossetto, S. (1995a), “QFD: the problem of comparing technical/ 
Fiorenzo Franceschini and Carlo Rafele

Quality evaluation in logistic services

International Journal of Agile Management Systems

2/1 [2000] 49-53 engineering design requirements", Research in Engineering Design, Vol. 7, pp. 270-8.

Franceschini, F. and Rossetto, S. (1995b), “Quality \& innovation: a conceptual model of their interaction”, Total Quality Management, Vol. 6 No. 3, pp. 221-9.

Franceschini, F. and Rossetto, S. (1997), "Design for quality: selecting product's technical features”, Quality Engineering, Vol. 9 No. 4, pp. 681-8.

Franceschini, F. and Rossetto, S. (1998), "On-line service quality control: the "qualitometro" method”, Quality Engineering, Vol. 10 No. 4, pp. 633-43.

Franceschini, F., Cignetti, M. and Caldara, M. (1998), "Comparing tools for service quality evaluation”, International Journal Of Quality Science, Vol. 3 No. 4, pp. 356-7.

Frizziero, F. and Rafele, C. (1996), "La misurazione delle performance logistiche", Logistica, Vol. XXVII No. 5, pp. 96-101.

Hayes, B.E. (1992), Measuring Customer Satisfaction, ASQC Quality Press, Milwaukee, WI.

Kano, N., Seraku, N., Takahashi, F. and Tsuji, S. (1984), "Attractive quality and must-be quality”, |Measuring Customer Satisfaction Vol. 14 No. 2, pp. 39-48.

Negri, L. (1993), "La qualità nelle imprese di servizi”, Spazio Impresa, No. 26, pp. 20-4.
Parasuraman, A., Zeithaml, V.A. and Berry, L.L. (1985), "A conceptual model of service quality and its implications for future research", Journal of Marketing, Vol. 49, pp. 41-50.

Parasuraman, A., Zeithaml, V.A. and Berry, L.L. (1988), "SERVQUAL: a multiple-item scale for measuring consumer perception of service quality”, Journal of Retailing, Vol. 64 No. 1, pp. 12-40.

Parasuraman, A., Berry, L.L. and Zeithaml, V.A. (1991), "Refinement and reassessment of the SERVQUAL scale”, Journal of Retailing, Vol. 67 No. 4, pp. 420-50.

Shapiro, R.D., Watkins, M.D. and Rosegrant, S. (1997), "Measure of delight: the pursuit of quality at AT\&T Universal Card Services”, Harvard Business School Report, 9-694-047.

Teas, R.K. (1993), "Expectations, performance, evaluation, and consumers' perceptions of quality”, Journal of Marketing, Vol. 57, pp. 18-34.

Van Amstel, R.P. and D'hert, G. (1996), "Performance indicators in distribution", International Journal of Logistics Management, Vol. 7 No. 1, pp. 73-82.

Zeithaml, V.A., Parasuraman, A. and Berry, L.L., (1990), Delivering Quality Service, The Free Press, New York, NY. 